\title{
An app based on cooperative learning for the detection of danger points and the prevention of risk areas in a city
}

\author{
Aldo Alexis Pérez Vizcarra \\ Universidad Nacional de San Agustín de Arequipa \\ Arequipa, Peru \\ aperezviz@unsa.edu.pe \\ Jaison Willian Torres Chana \\ Universidad Nacional de San Agustín de Arequipa \\ Arequipa, Peru \\ jtorresch@unsa.edu.pe
}

\author{
Guadalupe Paulina Anccasi Figueroa \\ Universidad Nacional de San Agustín de Arequipa \\ Arequipa, Peru \\ ganccasi@unsa.edu.pe
}

\author{
Francisco José García-Peñalvo \\ Universidad de Salamanca \\ Salamanca, Spain \\ fgarcia@usal.es
}

\begin{abstract}
This article gives a general review of the presence of crime in today's society, its impact in the daily life of the citizens and proposes the use of Safe Paths, a mobile application focused on risk prevention based on social collaboration and cooperative learning to identify dangerous areas and give alerts based on their users' location and the risks around to them. It also describes some technical aspects of Safe Paths such as its architecture from the MVC approach; the use cases and actors involved in said application and finally shows its graphical user interface.
\end{abstract}

\section{KEYWORDS}

crime, prevention, mobile application, crowdsourcing, geolocation.
International Conference on Technological Ecosystems for Enhancing Multiculturality (TEEM 2019) (León, Spain, October 16-18, 2019), ACM, New York, NY, USA, 10 pages. https://doi.org/10.1145/3362789.3362929

\section{Introduction}

Citizen insecurity is one of the main problems in today's society and unfortunately, due to its high increase citizens have led it to its naturalization. However, regardless of whether the perception of insecurity fluctuates, it persists and governs the behavior of a good part of society [13] [14]. This situation leads the citizens to express their preference for more drastic measures, which even put their human rights at risk [16]. Despite the various efforts of the authorities to combat this problem, they rarely become effective because they do not usually have the necessary impact or the required diffusion to face it [17] because many times citizen participation as part of strategic planning is underestimated or minimized, without mentioning that many of the public security policies are oriented on the reaction to events that have already happened, instead of concentrating firmly on following a prevention policy [10].

In today's society, where we have chosen to include the use of Information and Communication Technology (ICT) [12], it is common to bet on the creation of intelligent systems in various sectors, which usually have positive effects and generate inclusive social models making cities more attractive for their citizens [15] [11] and because their presence and impact is growing, it is important to take advantage of the opportunities that offers us [20]. It is in this kind of environments where crowdsourcing has become a very important tool for the search of solutions based on the information provided by the community and the enrichment through the generated interactions [21], in such way that it becomes a useful way to capture information, synthesize it and generate knowledge related to different social problems [7].

Crowdsourcing also uses strategies such as collaborative and cooperative learning because it involves the exchange of knowledge between people. Both strategies are based on the principle that learning is inherently a social process, because it 
gives those involved the ability to interact with each other to solve problems together. Cooperative learning is a special type of collaborative learning in which small groups work together in well-structured activities, guided by clear objectives, where each group is guided and evaluated. Its main difference with collaborative learning is that cooperative learning focuses solely on the effectiveness of cooperation [5]. However, in order for the information collected from users to be used effectively, it must not only be stored, but must also be analyzed and processed properly, which would improve the interpretation of the information acquired, allow the social behavior of citizens to be analyzed, It would allow us to make better decisions and even predict adverse situations and prepare ourselves adequately to face them.

It is also important to implement an appropriate interaction model that takes advantage of the capabilities of current technology, which would allow communicate to the users effectively the information that is intended to be shared with them and its easy and quick interpretation. If the interaction model is properly designed could be applied to many areas, which would allow a wide variety of applications.

One of the areas in which technology should have a fundamental role is public security, because this is a basic requirement for the development of the human being and for his general well-being. The incorporation of technology in this area would allow a more adequate analysis of the problem to fight and a more effective strategic management to face it [15]. However, a security application that uses ICT as the base of its operation must have a simple and intuitive interface. Due to this, a good design from the perspective of the Human-Computer Interaction (HCI) is essential [18] [8]. This includes considering usability attributes such as efficiency, user satisfaction, learnability, memorability and fault tolerance [19].

In this work, Section 2 provides details of the proposed mobile application called Safe Paths and includes an overview about its architecture. Section 3 provides a description of its user interfaces. Section 4 contains the discussion. Conclusions are provided in Section 5.

\section{Safe paths as an alternative for insecurity}

The application described in this article arises as a project of a group of students of Computer Science of the National University of San Agustín of Arequipa in the city of Arequipa in Peru and represents a proposal based on ICT to combat the aforementioned problems offering the users an option that allows them to face the risks present in their city.

Safe Paths is an application that uses geolocation through the Global Positioning System (GPS), in addition to an internet connection to share information related to security issues, which is then processed to provide alerts and suggestions.

The application stores the reports provided by users to share them with the community. Through these reports, is where information is collected about the incidents of danger that occur in their city, information that includes a specific street, an incidence of a list of certain incidents, the frequency with which this incident occurs and some additional comments. Temporary information such as the date and time of registration is also stored. 


\subsection{Safe Paths' Architecture}

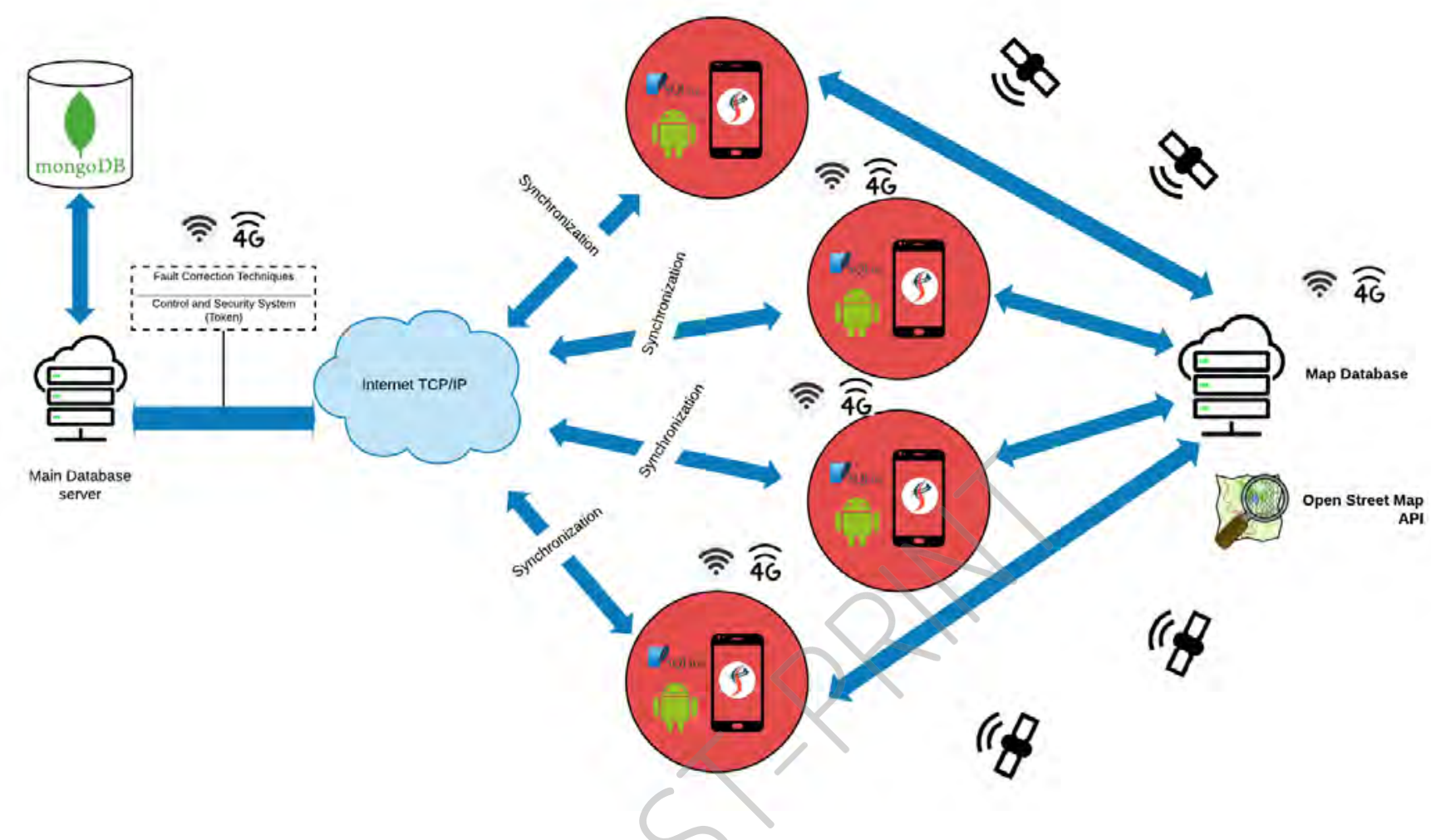

Figure 1: Figure Caption and Image above the caption [In draft mode, Image will not appear on the screen]

The architecture used in the Safe Paths development is shown in Figure 1, where each of the components that intervene in the application can be identified. Here we can see that each user of the application is identified independently by a red circle and has a local SQLite database [4]. SQLite was chosen because it has a light, autonomous, simple configuration and not requiring a server, it is characterized by storing persistent information in a simple way adapting to Android OS.

The main database hosted on the cloud server uses MongoDB [2], a general purpose, document-based, distributed database built for the cloud era. This database was chosen because is open source database and free to use and one of the most important features it has is its scalability, because it can handle a large flow of users without this being a problem. Safe Paths performs a synchronization and update of the local database in each of the mobile devices. This will happen every time the application detects the addition or modification of information in the main database hosted in the cloud. For this is essential to have an Internet connection enabled as shown in Figure 1.

In this process, the following should be taken into account:

- Control and security system (Token management).

- Shared resources.

- Concurrences.

- Scalability.

- Fault Tolerance.

- Transparency for the mobile user.

- Quality of service provided by Safe Paths.

- Actions and reports to the main database server. 


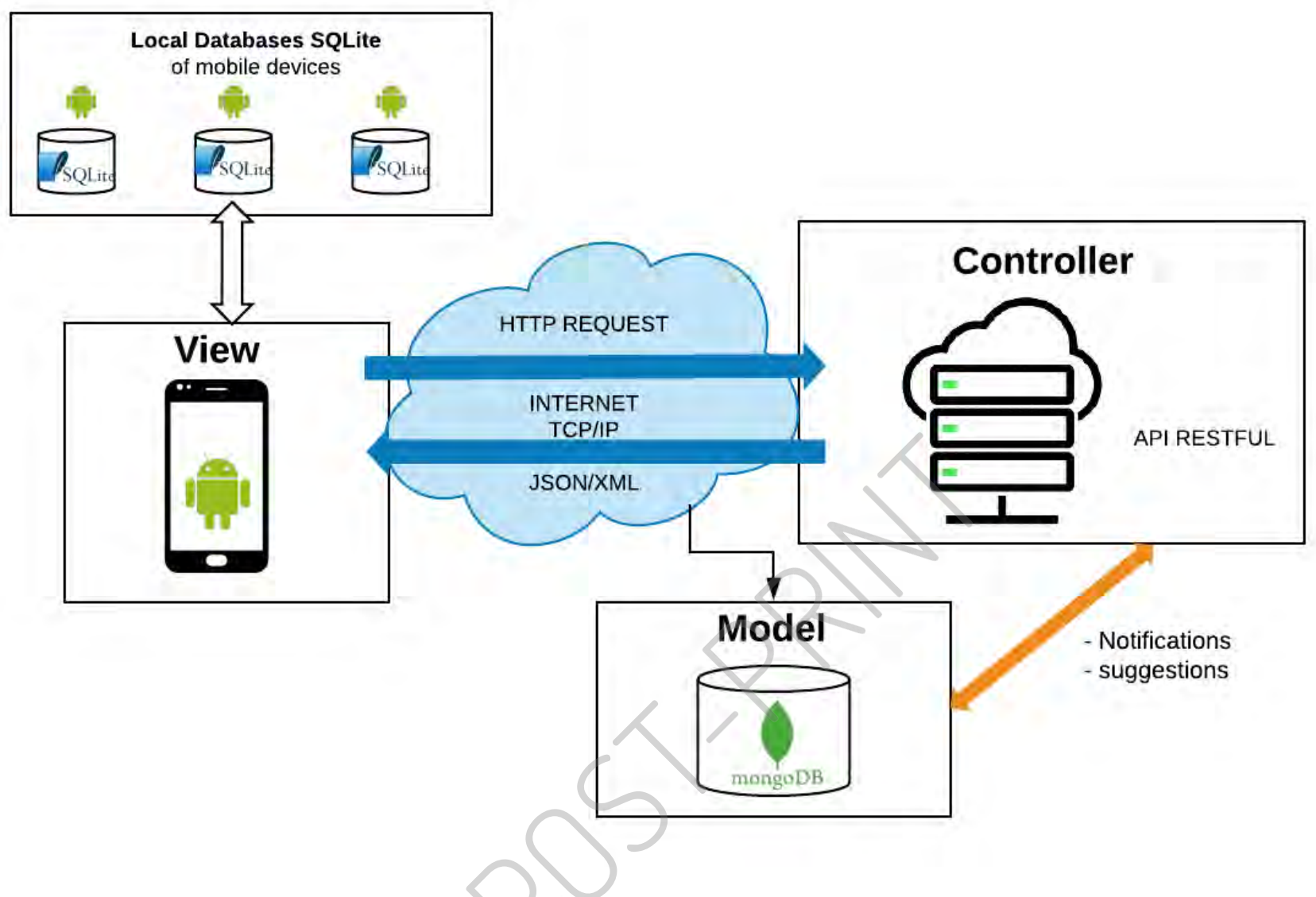

Figure 2: Figure Caption and Image above the caption [In draft mode, Image will not appear on the screen]

The application uses the services provided by the Global Positioning System [1]. This allows obtaining the current position of an object in the whole world from space and provides separately three-dimensional coordinates of latitude, longitude and altitude. In addition, Safe Paths uses the map services offered by OpenStreetMap [3], a project aimed at creating and offering free geographic data to the world, this allows access to map information at the geographical level.

Figure 2 shows a diagram based on the Model-ViewController to detail the logic used in the Safe Paths architecture [6]. It is observed that the information that the View receives and that will be displayed in the user interface is in JSON, XML format or plain text.

The View communicates with the Controller, which contains the communication methodology that is given through the WebSocket technology that will be useful for the synchronization that takes place every certain time between the local Databases and the main cloud database, sending http requests over the Internet. After processing the request, a response is given in files with JSON or XML format.
Finally, it is shown that the Model is divided into two parts that comprise the databases that are used for this architecture. On the one hand, there is the mongoDB main database, which connects with the Controller, in order to make updates, notifications, etc. On the other hand, there are local SQLite databases stored in each of the mobile devices, shown in the upper part of Figure 2, which have communication with the View and are part of the Model.

\section{Safe paths' interaction model}

\subsection{UML diagram of Safe Paths' Use Cases}

The use case diagram shown in Figure 3, describes the functions performed by each actor.

- Actor

a. User: The person who will use Safe Paths.

b. Global Position System: The system that provides the precise and current location of the user. 
c. MongoDB server: It is responsible to store the necessary information of the dangerous streets.

d. Local database: It is responsible for storing the general information of the application and users.

- $\quad$ Use Cases

a. The user has to register and validate their data appropriately.

b. When the user enters Safe Paths, he/she will be able to visualize a map with the dangerous zones that have been identified close to their position. c. The user can search for any address simply and quickly through the application.

d. The user will be warned before approaching a dangerous street by activating the danger radar.

e. The user will be able to rate a dangerous street in a simple way.

f. Safe Paths will update the user's map information by asking the Server if there is any modification or not.

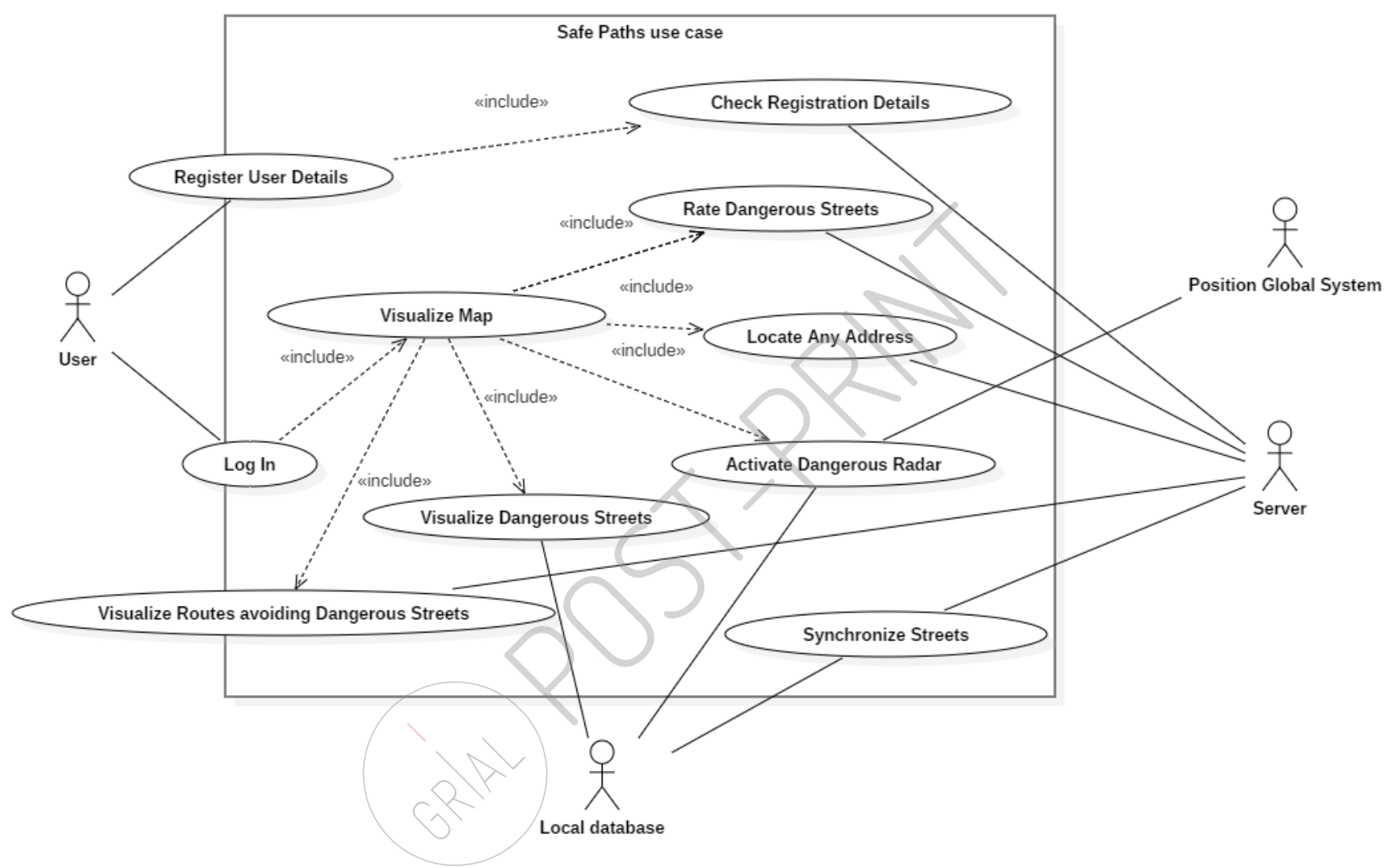

Figure 3: Figure Caption and Image above the caption [In draft mode, Image will not appear on the screen]

\subsection{Safe Paths' User Interface}

After downloading and installing the application, users will find a registration screen in which they must enter their data. Later, with the GPS service and the Internet connection enabled, they will be able to use the application's functionalities.

Safe Paths presents a list of incidents, which comprises from criminal acts like gunpoint robbery to street sexual harassment cases. Due to the interpretation of risk can be variable and is always changing, this list of incidents has been designed to be updated and renewed over time, giving the application the ability to adapt to new risks or dangers that may arise in our society.

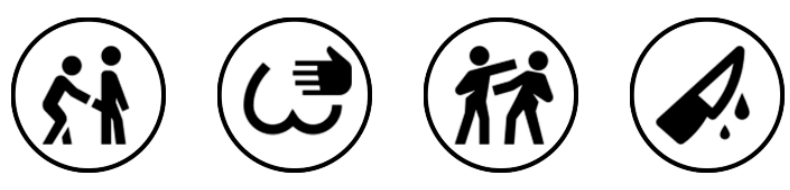

Figure 4: List of incidences

The color scale used in Safe Paths is comprised of yellow, orange and red. This scale shows the frequency with which a certain criminal act can occur where yellow represents a lowest frequency and red, the highest frequency the users can register. 

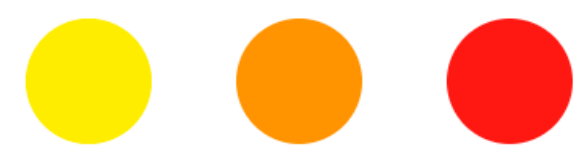

Figure 5: Scale of colors used to indicate the frequency of criminal acts

The screenshots shown below correspond to the prototype of the second version of the application, which is still in the development phase.

The application shows on its main screen a map, user's location in real time and a series of alerts that indicate the risks present in the proximity (Figure 6). In this screen, the user could also enter a destination to which he wants to move and the application will offer a route that avoids streets marked with a certain risk index by Safe Paths user community (Figure 7).

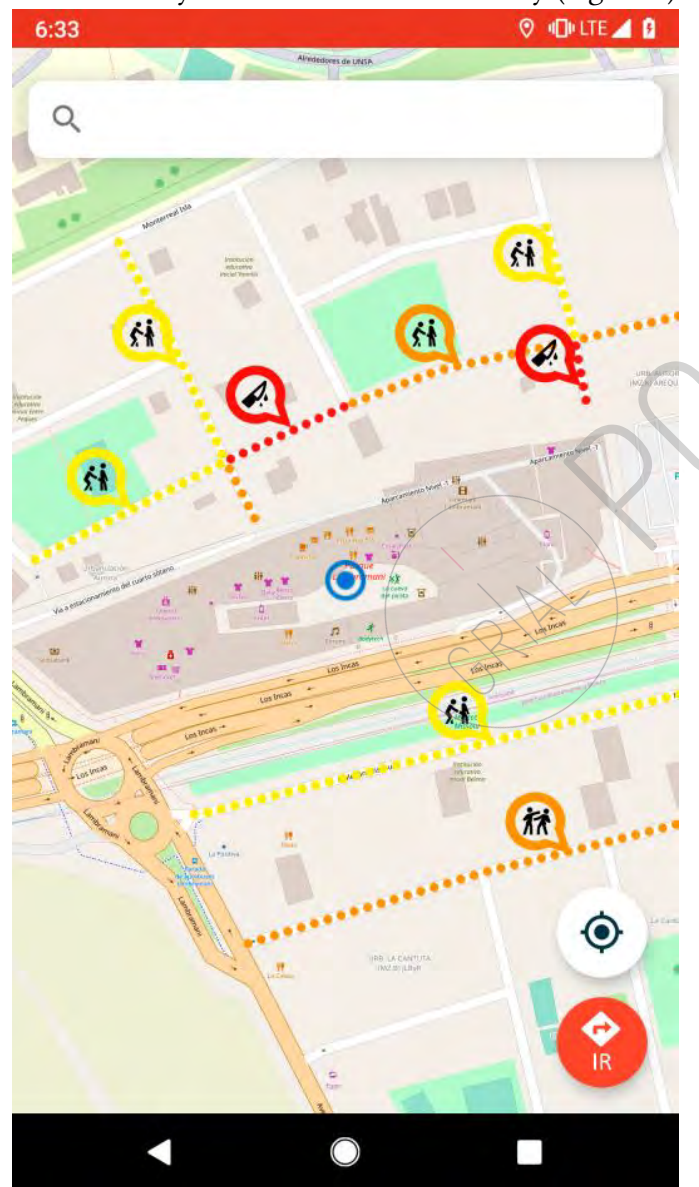

Figure 6: General view of the map offered by Safe Paths in which dangerous areas are marked around the user

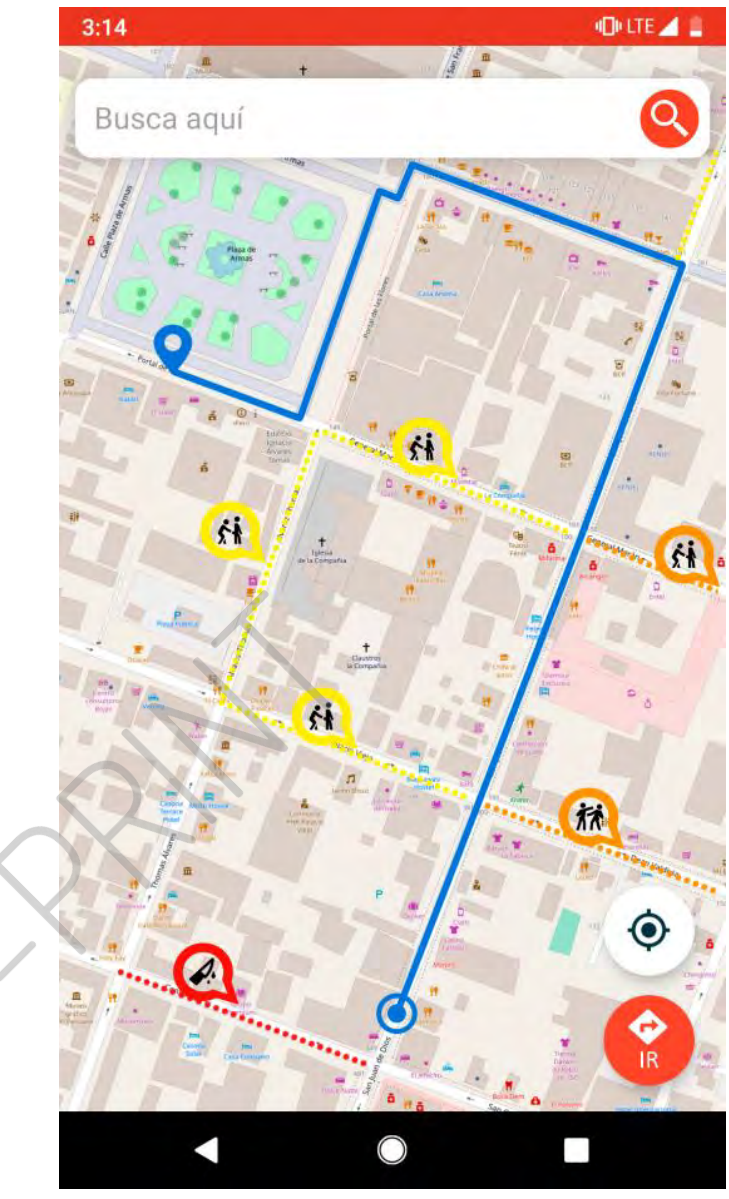

Figure 7: Route offered by Safe Paths that avoids dangerous streets

Safe Paths also allows users to add information to the database in order to share it with others who use the application. To do this, it is only necessary to mark on the map a specific street, select the incidence that the user wants to report and the frequency of that, and finally, they can add some additional comments (Figure 8). 


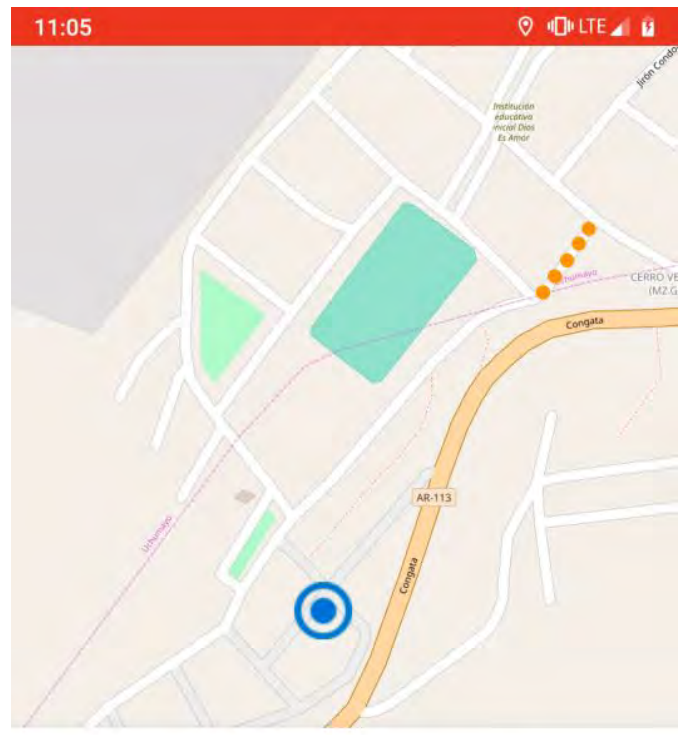

Incidencia:

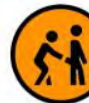

Frecuencia

Comentarios adicionales

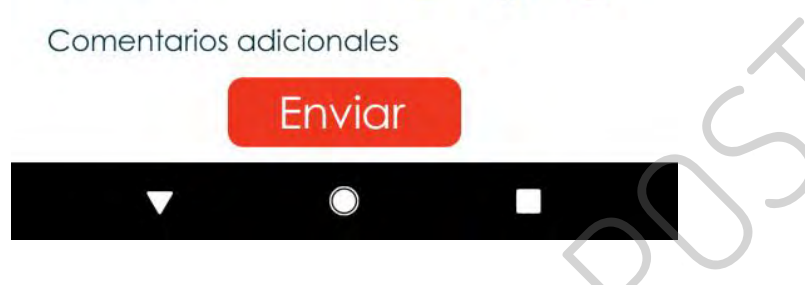

Figure 8: Rating interface for new dangerous streets

Another feature included in the application, is the ability to warn the users when they are approaching to a place reported as dangerous through a notification. This notification will show essential information on screen and it will be accompanied by customizable sounds and vibration (Figure 9).

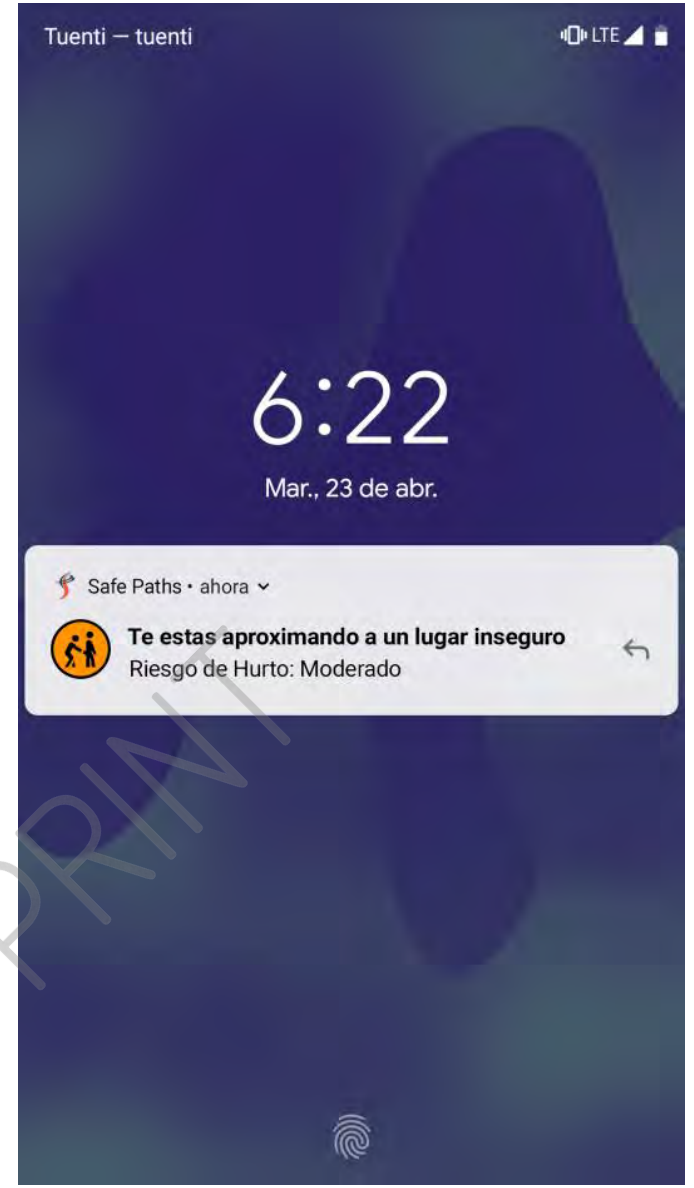

Figure 9: Safe Paths notification when a user approaches a risk zone

\section{Discussion}

Geographic Information Systems (GIS) are popular tools that have proven to provide great support for geographic intelligence tasks such as traffic management, geographical location and even the identification of risks. However, many of them only give a quick response to the reports made by users and just show some basic information to them, often in a limited and uninteractive way [9].

The application described in the present article has the purpose of combining three technological elements with geographic information systems: Mobile devices, the approach of extraction of information by users, also called crowdsourcing, and storing and processing of reports based in geolocation. In addition to all this, it is also focused on prevention as a main task, with the primary objective of getting the users to reach their destination avoiding dangerous places that may be around them. Safe Paths also keeps them informed of the latent risks through sounds and vibrations, which are activated before it approaches a dangerous place. This application also can provide 
to the authorities and police forces with a hazard map created from the contributions of users, so that they can plan better strategies to combat crime, concentrating better the areas of police patrol and the authorities' action, thus achieving a more direct participation of citizens in public safety and risk prevention policies.

Safe Paths has been developed with the goal of having a global reach, in addition to facilitating the incorporation of new features that can ensure that the information provided to the user is much more accurate. Future versions of the application could include, in addition to performance improvements and corrections of some bugs, the incorporation of artificial intelligence algorithms, which allow analyzing and predicting criminal behavior, taking as reference a certain time of day or a certain month of the year. Besides not only will be limited to the criminal area, but also to other types of risks present in society, which may affect small and often ignored segments of the population.

\section{Conclusions}

Based on the final discussion, it is possible to conclude that the combination of mobile technologies, the telecommunications infrastructure present in urban areas and the crowdsourcing model represent a viable alternative to face crime issues in society, as well as problems of similar nature. In addition, the danger maps obtained by Safe Paths not only give the users of the mobile application the possibility to prevent crime and avoid the risk areas present in a certain city, they also to warn the authorities of the locations where crimes are committed recurrently. Moreover, the way in which this application has been designed, allows the incorporation of new functionalities that would make it into a tool focused on the prevention of multiple risks.

\section{REFERENCES}

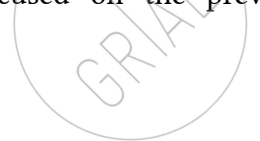

[1] [n. d.]. GPS: The Global Positioning System. https://www.gps.gov

[2] [n. d.]. MongoDB. https://www.mongodb.com/

[3] [n. d.]. OpenStreetMap. https://wiki.openstreetmap.org/wiki
[4] [n. d.]. SQlite. https://www.sqlite.org/index.html

[5] Abdelaziz Bouroumi and Rkia Fajr. 2014. Collaborative and cooperative elearning in higher education in Morocco: A case study. International fournal of Emerging Technologies in Learning (ifET) 9, 1 (2014), 66-72.

[6] Frank Buschmann, Regine Meunier, Hans Rohnert, Peter Sommerlad, and Michael Stal. 1996. Pattern-Oriented Software Architecture - Volume 1: A System of Patterns. Wiley Publishing.

[7] Matías Herrera Cáceres. 2017. Crowdsourcing y datos abiertos a través del uso de tecnologías móviles como instrumento de participación ciudadana en la ciudad de San José de Cúcuta. Cuaderno Activa 9 (2017), 37-49.

[8] Jethro B de Guzman, Remedios G Ado, et al. 2014. Mobile emergency response application using geolocation for command centers. International fournal of Computer and Communication Engineering 3, 4 (2014), 235.

[9] Abraham Espinoza-Ramírez, Mariko Nakano, Gabriel Sánchez-Pérez, and Antonio Arista-Jalife. 2018. Sistemas de Información Geográfica y su Análisis Aplicado en Zonas de Delincuencia en la Ciudad de México. Información tecnológica 29, 5 (2018), 235-244.

[10] Eduardo Vega Fernández. 2017. El control y la prevención del delito como objeto de la criminología. Miscelánea Comillas. Revista de Ciencias Humanas y Sociales 75, 146 (2017), 171-194.

[11] David Fonseca and Francisco J. García-Peñalvo. 2019. Interactive and Collaborative Technological Ecosystems for Improving Academic Motivation and Engagement. Universal Access in the Information Society (2019).

[12] David Fonseca, Miguel Ángel Conde, and Francisco J García-Peñalvo. 2018 Improving the information society skills: Is knowledge accessible for all? Universal Access in the Information Society 17, 2 (2018), 229-245.

[13] Sergio García García and Débora Ávila Cantos. 2016. La prevención securitaria como modo de gobierno: el caso de Madrid. Athenea Digital. Revista de pensamiento e investigación social 16, 1 (2016), 43-82.

[14] Ana Cecilia Morquecho Güitrón and Lorenzo Rafael Vizcarra Guerrero. 2017. Inseguridad pública y miedo al delito, un análisis de las principales perspectivas teóricas y metodológicas para su estudio. Letras jurídicas 6,6 (2017).

[15] Alexandru Iancu et al. 2016. Nuevas tecnologías, policía y prevención del delito. (2016)

[16] David Pion-Berlin and Miguel Carreras. 2017. Armed forces, police and crimefighting in Latin America. Journal of Politics in Latin America 9, 3 (2017) 3-26.

[17] David Ramírez-de Garay and Mario Pavel Díaz Román. 2017. Los efectos de la política de prevención del crimen y la violencia en México/The effects of prevention of crime and violence policy in Mexico. revista cidob d'afers internacionals (2017), 101-128.

[18] Shraddha Save, Mansi Gala, Surabhi Patil, and Dhananjay R Kalbande. 2015 Applying human computer interaction to individual security using mobile application. 2015 International Conference on Communication, Information \& Computing Technology (ICCICT). IEEE, 1-6.

[19] Samar Swaid. 2017. Usability of Mobile Apps: An Integrated Approach.

[20] Sonia Montserrat Vaz Veiga. 2017. LA CULTURA DE LA PARTICIPACIÓN EN LA SOCIEDAD DEL CONOCIMIENTO. LA CULTURA (2017).

[21] Zheng Xu, Yunhuai Liu, Neil Yen, Lin Mei, Xiangfeng Luo, Xiao Wei, and Chuanping Hu. 2016. Crowdsourcing based description of urban emergency events using social media big data. IEEE Transactions on Cloud Computing (2016). 